\title{
Muerte y traducción en la escritura de Pascal Quignard
}

\author{
Melina Balcázar Moreno
}

Este artículo explora la faceta del escritor Pascal Quignard como traductor y su postura frente a una tarea imposible. Más que entablar un diálogo con su tiempo, al traer las palabras de otra lengua a la suya, Quignard asume que la traducción es una relación con la muerte y con los muertos. "Traducir es ayudar a hablar al muerto", escribe Quignard, y de esta frase partimos para mostrar su manera de abordar los problemas de la compenetración y la rivalidad del traducir, rozando al mismo tiempo lo que escapa irremediablemente al sentido.

PALABRAS ClAVE: Quignard, traducción, muerte, duelo, Celan.

This article explores the facet of the writer Pascal Quignard as a translator and his point of view about an impossible task. Rather than engaging in a dialogue with his time, to bring the words of another language into his own, Quignard assumes that translation is a relationship with death and the dead. "Translating is to help people talk to the dead", writes Quignard, and from starting with this phrase, we begin to show how he takes on problems to the bonding and rivalry of translation, touching at the same time on what irretrievably escapes the senses.

KEYWORDS: Quignard, translation, death, mourning, Celan.

Fecha de recepción: 3 de septiembre de 2014

Fecha de aceptación: 6 de octubre de 2014 



\author{
Melina Balcázar Moreno \\ Sorbonne Nouvelle - Paris 3, Francia \\ melinabalcazar@gmail.com
}

\title{
Muerte y traducción en la escritura de Pascal Quignard ${ }^{1}$
}

No, no, la obra de arte no se destina a las generaciones infantes. Se ofrece al innumerable pueblo de los muertos. Que la aprueban. O la rechazan.

JEAN GENET

Pascal Quignard establece en Zétès una inquietante relación entre traducción y muerte: "Traducir es ayudar a hablar al muerto" (Quignard 2010: 276). Así se revela esta relación, en una época que intenta hacer que la vida se vuelva plenamente presente, ocultando a los muertos mediante una división espacial, emocional y psíquica, que los separa radicalmente de los vivos. Inquietante lo es también para aquel, para aquella, que trata de dejar tras de sí la muerte, de terminar con ella y con sus muertos.

La traducción es aún más perturbadora puesto que involucra al cuerpo. De esta manera, la reina Alcestis - que, nos recuerda el escritor, bajó a los Infiernos en lugar de su esposo- se convierte en traductora, al ofrecer su vida y su voz al muerto (Quignard 2002: 276).

${ }^{1}$ Todas las traducciones de las citas en francés en el presente artículo son de mi responsabilidad. Una primera lectura se realizó en presencia del autor durante el coloquio Pascal Quignard. Translations et métamorphoses, que tuvo lugar en julio de 2014, en el Centro Cultural de Cerisy-la-Salle (Francia), organizado por la Universidad Sorbonne Nouvelle y el centro de investigación ITEM/CNRS. Se ha respetado la complejidad de los textos en francés e incluso la "invención" de palabras, poco comunes o inexistentes en la lengua de origen. 
En la obra de Pascal Quignard pueden leerse varias tentativas de definición de esta práctica, que ocupa un lugar privilegiado entre sus diferentes quehaceres (Quignard se dedica también a la música, el dibujo, la lectura, la edición). Para él, la traducción es ante todo imposible. De esta manera hace suya la afirmación del helenista Jean-François Boissonade, con respecto a la traducción francesa de la Alejandra de Licofrón, quien sostenía que no era posible traducirla en vista de su carácter oscuro. Quignard escribe en el primer prefacio a su traducción de este complejo texto:

Las palabras de Boissonade, siempre las mismas cualquiera que sean, ante toda obra, son las mismas, y aquí indistintamente: ahora más que nunca. Puesto que a partir de ahora se ha alterado la seguridad que ofrecía tal garantía quizás, que un texto, fuese como fuese, de cualquier forma, pudiera ser traducido. La época en que tal pretención iba de sí, en la evidencia, a partir de un lugar del sentido determinado en cuanto representación $[\ldots]$ - eso, una época así ya no es segura. En ese lugar perdido o alterado, nada que ahí pueda nunca equivaler (Quignard 2010: 135).

Nada hay en común entre las lenguas, sólo una "imposible equivalencia" que obliga al traductor a encontrar otra forma de proceder, que no pretenda ser una "refección": "Traducción que ya no sea más restitución sino el hecho de una repetición. Por consiguiente, traducir, leer y escribir son lo mismo —o su diferencia desesperada - Repetir y traducir son ese gesto mímico, palabra por palabra, del mismo traducir palabra por palabra, que se encuentra menos a la escucha de sí que del texto que resurge con la fuerza de esta aparición" (135).

Se trata entonces de "tonos", de "tensión", de "trueno". La traducción es ante todo una cuestión de energeia, de la fuerza que resulta de la confrontación entre las lenguas. La tarea del traductor es "mímica": es decir, hacer resurgir la gestualidad de las palabras a partir de ese gesto, que escarba obsesivamente en la etimología de cada palabra, a fin de extraer su fuerza.

Esta idea recuerda el prefacio que Pierre Klossowski escribió para su traducción de la Eneida (1964) al francés: "El poema épico de Virgilio es [...] un teatro donde las palabras mimetizan los gestos y el estado de 
ánimo de los personajes, de igual forma que mediante su disposición, mimetizan también los accesorios propios de la acción. Las palabras son las que adoptan una actitud y no los cuerpos; las que se tejen y no las vestimentas; las que centellean y no las armaduras; las que estallan y no la tormenta; [...] las que sangran y no las heridas" (Klossowski citado por Berman: 126).

Para traducir, según Pascal Quignard, hay que "repetir el texto - no como tal—, sino su fuerza". Es esta fuerza la que tiene que respetarse a pesar de lo que pueda ocurrirle a la lengua propia, la que recibe la palabra extranjera. Y añade: "Respeto significa aquí una verdadera obediencia”. Para traducir, entonces, hay que obedecer, ponerse a la escucha de la voz que precedió al texto para encontrar de esta manera su ritmo. "Le gusta a uno traducir — nos dice todavía — desde el momento en que se desea someterse en cuerpo y alma a un texto dominante" (Quignard 2010: 166-167). Obediencia no implica, sin embargo, sujeción. El traductor que imagina, el que él mismo es, no copia tal cual de manera ingenua o servil la sintaxis griega u otra; lo que él traduce no es la distribución factual de los accidentes sintácticos sino su sistema global (Berman: 130). El escritor-traductor va todavía más lejos al asociar esta mímica con la "impostura" y la "simulación". En uno de sus Pequeños tratados, Quignard incluso afirma: "Traducir es seguir el texto del que uno se aleja. Es rozar los fantasmas de las lenguas mismas y, en la compenetración y la rivalidad del traducir palabra por palabra, rozar al mismo tiempo el sentido inexpresable, el caos y la falta de sentido, en razón misma del exceso de sentido: la Infiel, lo Inatribuible, el Contrasentido, el Falso sentido, el Sin sentido, son los verdaderos fantasmas" (Quignard 2002: 499-500). Las traducciones que aparecen en su obra dan cuerpo a estos sentidos fantasmáticos que exceden al texto por traducir.

Es tal vez lo que significa Lêxo, la primera palabra del poema de Licofrón, a la que vuelve una y otra vez a lo largo de Zétès, como testimonio del lazo que unió a Quignard con Paul Celan. Lêxo no apela a un decir en presente sino a un decir suspendido, ese enigmático "diré" que oscurece la palabra del poeta y de su traductor. "El futuro es lo que se cifra, en lo que respecta al tiempo" (Quignard 2013: 45).

Quizá se deba al carácter paradójico de su apego a la letra, a sus posibilidades, que el enfoque de Quignard ha sido interpretado como una 
prolongación, e incluso como un "elogio" de la tradición en Francia de las "bellas infieles". Desde esta perspectiva filológica, que se concibe como respetuosa del original, sus traducciones pueden parecer "erróneas", "falsas" y las consecuencias de sus "faltas de traducción", resultar "graves" (cfr. Gorrillot: 210-211). ${ }^{2}$ Pero como él mismo lo confiesa, su traducción de Alejandra es "desde cualquier punto de vista indefendible" (Quignard 2010: 153). Aunque su enfoque no le autorice una libertad poética que, en nombre de la soberanía creadora, justificaría que su voz se superponga a la del texto por traducir, su objetivo no es, contrariamente a la traducción filológica, restituir el sentido de los textos, de ser "correcto (del lado de la lengua a la que se traduce) y exacto (del lado del texto por traducir)" (Berman: 119). A pesar de que, como lo señala Bénédicte Gorrillot, "traducir transporta inevitablemente las marcas del sujeto que lee", esto no supone que, como lo afirma la estudiosa, dichas marcas hagan desaparecer las "huellas que dejó el otro sujeto, es decir, el autor del texto que se descifra" (Quignard 2011b: 135).

Habría entonces que plantear de otra manera este problema. La traducción en Pascal Quignard no intenta ser fiel sino literal. De esta manera, practica una traducción palabra por palabra que vuelve extranjera la lengua materna. Recuerda en Lecciones de solfeo y de piano las composiciones que hacía con Klossowski en los años setenta: “Tratábamos de traducir pegando las palabras de la lengua de llegada a la sintaxis de la lengua de partida. [...] nos encantaban esos ejercicios que desnaturalizan de arriba abajo la lengua. [...] Nos parecía cada vez algo milagroso y, en cierto aspecto, algo teológico. La lengua materna se volvía bárbara" (Quignard 2013: 35). Arriesgado es ese placer que se encuentra en alejarse de su lengua - materna, nacional-, en violentarla al introducir al centro de la exigencia de inteligibilidad una lengua otra, que paradójicamente permite desvelar sus posibilidades latentes.

Sin abolirla, acentúandola incluso, Pascal Quignard confronta la distancia que separa a las lenguas. Así, traducir se vuelve un ejercicio para "afrontar el intervalo físico y errático que de repente se sitúa entre las dos lenguas". Para traducir literalmente, debe conservarse en la lengua que

${ }^{2}$ Por ejemplo, su práctica privaría así al latín de ciertas de sus características, como su sistema temporal jerarquizado (cfr. Gorrillot: 214). 
traduce "el espejismo de frase que permanece entre dos lenguas y que es invisible a los ojos de todos" (Quignard 2010:178). Probablemente lo que resulta más difícil para quien traduce es mantener la tensión entre lectura y escritura, logrando al mismo tiempo hacer sensible este intervalo que, como un abismo, las separa.

No obstante, para "traducir verdaderamente" (Quignard 2002: 499), hay que multiplicar las palabras, aumentarlas (cfr. Quignard 2013: 44). Es justamente lo que enfatiza el escritor Emmanuel Hocquard con respecto a su primera traducción del poema que Pascal Quignard escribió en latín en 1976, en un momento de profunda tristeza: "Recuerdo que cuando traduje Inter aerias fagos con él en Malakoff, [...] tomamos partido - la propuesta vino por cierto de Pascal mismo - para darle a la palabra latina varias traducciones posibles, unas seguidas de otras, cuando nos parecía que podía esclarecerla. Tradujimos así saltus por: ‘ $i$ l afuera! ¡Lo sin lenguaje! Más lejos que el final del campo, el exceso de vegetación expone la cosecha. Una región salvaje" (Emmanuel Hocquard en Quignard 2011b: 149-150).

"Verdaderamente" es aquí la marca, no de la adecuación a la verdad del texto por traducir sino de la exigencia que se impone al traductor de arriesgarse al exceso de significación, a "la demasía o la extenuación" (Quignard 2010: 126). En efecto, resulta agotador "el pensamiento que avanza letra por letra, literario, literal" (211).

Pascal Quignard tradujo de esta forma la Alejandra de Licofrón hace más de cuarenta años. Regresa a ese largo trabajo solitario en su postfacio de 2009, que acompaña su reedición, curiosamente en una colección de poesía, aun cuando el largo texto que acompaña su traducción, Zétès, sea una serie de tratados en prosa. Reinscribe así en el curso actual de su escritura ese primer texto que da testimonio de lo que él llama el "mundo de entonces", así como de sus "modelos", Heidegger, Paul Celan, André du Bouchet, Louis-René des Fôrets... Fue para él una época de silencio, de profunda depresión cuya causa se le revelará más tarde durante las sesiones de psiconálisis que siguió durante varios años: fue la pérdida de una lengua, la pérdida de una mujer, la primera, la joven alemana que lo crió de pequeño mientras su madre estaba enferma. Vive entonces su práctica de la traducción como un largo viaje a otro mundo, 
que solamente su trabajo etimológico hace posible: "Me adentraba en los siglos perdidos. Abordaba el país de los muertos. Iba a buscar los étyma en los juncos, cerca de las sombras en el agua muerta. Penetraba en la lengua muerta. Tenía en verdad una impresión de Nèkyiia" (Quignard 2010: 138).

La traducción va más allá del saber, se vuelve una cuestión vital. La lengua muerta - el griego, el latín — se le revela como una oportunidad que le permite encontrar un "enlace" (Quignard 2002: 173) con lo que se ha perdido, como la cabaña de Todas las mañanas del mundo, que alejada del mundo ofrece una invisibilidad protectora: "Toda traducción es una cabaña de Sainte-Colombe, establecida en una morera que ya no toca el suelo" (Quignard 2010: 149).

Callarse, ocultarse, confiarse a la sombra también es traducir. Tal vez es lo que dice el nombre de Celan a quien le debe su pasión por traducir (Quignard 2013: 41). Fue él, en efecto, quien le pidió que tradujera del griego. Su nombre, que ha quedado dolorosamente ligado a su suicidio, regresa de un texto a otro. En aquella época, nos dice Quignard, se le conocía sobre todo como traductor; Celan incitó a des Forêts y a du Bouchet a traducir también, "era nuestro Petrarca" (Quignard 2010: 151-152), según recuerda.

El nombre de Celan dice todavía el secreto de la pérdida oculta en el cuerpo, el secreto de la lengua que lo habitaba sin saberlo y que un día su pronunciación reveló. La lengua alemana vuelve cifrada en su escritura, como un signo de fidelidad hacia los muertos. Pero esta lengua estaba presente ya en su traducción del griego, en su escritura latina, como un tercero. "En una traducción, nos recuerda el pensador de la traducción Antoine Berman, opera siempre una tercera lengua. [...] Para toda traducción literal de un texto antiguo, el alemán es la referencia absoluta. Ya que es la única lengua occidental que, por intermedio de su poesía y su filología, por el de sus traductores, mantiene una relación tan íntima (aunque sin filiación) con el griego y el latín" (Berman: 137-138).

Quignard confía sus palabras a ese nombre que vela su origen - "Celan celant" (2010: 185) ("Celan cifrando" pues la " $t$ " del francés es muda y cuando se pronuncia se borra la diferencia entre el nombre y la acción) - para que puedan así llegar al otro: el ausente, la ausente que se encuentran al centro de la escritura. Y cita según su propia traducción 
un pasaje del Discurso de Bremen: "La botella que se lanzó al mar y que contiene algo escrito con tinta en un pedazo de papel debe por fuerza cerrarse herméticamente" (Quignard 2010: 185). Protegido del agua y de las lágrimas, el poema puede seguir llamando. La concepción misma de la lengua se pone en juego aquí y por ende la de la escritura. Una concepción que opuso de hecho a esos dos sobrevivientes que encontraron refugio en la lengua:

Primo Levi atacó una vez con violencia a Paul Celan. "Escribir es transmitir, dijo, no cifrar el mensaje y tirar la llave en los arbustos". Pero Primo Levi se equivocaba. Escribir no es transmitir. Es llamar. Tirar la llave es todavía otra forma de llamar a una mano que busque después de uno, que escarbe entre las piedras y las zarzas y los dolores y las hojas mojadas [...]. Y cifrar el mensaje es todavía llamar a la vista, requerir un saber que transmita lo que se ha perdido (Quignard 2010: 249).

Sin embargo, para Paul Celan y Primo Levi la lengua no fue suficiente. Su suicidio, como una letanía, como una queja - la de la Sibila en su Requiem - regresa una y otra vez.

El hermetismo no rechaza la comunicación, no implica un olvido del otro con el fin de imponer su firma. Si el "sello" debe formar parte del poema, es porque llama al "ausente", es decir, a "cualquier interlocutor al que se quiere hacer venir cerca de sí" (Quignard 2013: 30). Si se encierra su dolor, su sufrimiento en una carta, si se les cifra en ella y se escribe en una lengua que se ha vuelto hermética, puesto que nadie la habla ya, ni la transmite, es para formular este dirigirse al otro que perdura en el tiempo. Acerca de Inter aerias fagos, Pascal Quignard afirma en una carta: "escribo para algunos pocos lectores. Escribo para los muertos, para aquellos que decidieron no hablar, para los autistas" (2011a: 91). Como Petrarca, dirige su secreto a los muertos y escribe en latín. Insiste en esta elección citando nuevamente las palabras de Celan, en una traducción también suya: "Hay que cifrar su vida, tapar de nuevo la botella $[\ldots]$ pues se trata de enviarla muy lejos, más allá de la muerte, a quienes perdimos" (Quignard 2011a: 19).

Este dirigirse al otro se encuentra al centro del problema de la letra. Es lo que nos revela su traducción de un verso del poema de Celan 
"Sprich auch du" ("Habla también tú") de Von Schwelle zu Schwelle (De umbral en umbral, 1955) que aparece en Zétès y que difiere de manera fundamental de la que propone Maurice Blanchot en El último en hablar:

"Wahr schpricht, wer Schatten spricht" (Quignard 2010: 247).

- "Dit vrai, qui parle d'ombre", traduce Blanchot y que podríamos traducir a nuestra vez, palabra por palabra: "Dice verdad, quien habla de sombra".

- "Parle vrai, qui parle aux ombres", traduce Quignard, que podríamos traducir de la misma manera: "Habla verdad, quien habla a las sombras".

Se produce aquí un desplazamiento que va del absoluto de la palabra, que del puro hecho de su proferir tocaría lo verdadero a la interlocución en la escritura de Quignard, a la relación con este otro que permanece "invisible" y debe permanecer así. La persona, la segunda —-"tú"—llega entonces por intermedio de la sombra. Llega a la escritura ligado a la muerte.

"Ein Du, todlos" (Paul Celan, "Die Silbe Schmerz", Die Niemandsrose ), escribe Paul Celan, "Un tu sans mort", traduce Pascal Quignard dejando caer la letra capital y la interrupción de la coma que separaba al pronombre de la posibilidad de suspender la muerte. Ya que la muerte es, como nos dice en Una molestia técnica respecto a los fragmentos, "la puntuación más fuerte [...] el ritmo más fuerte, el más insistente y el más terrible" (Quignard 1986: 31). La posibilidad de una lengua mejor: "when one man dies one chapter is not turn out of the book but translated into a better language" (John Blow citado por Pascal Quignard en uno de sus dibujos).

Este "tú", que dice también el silencio, se queda en el cuerpo y puede situarse, según la permutabilidad de las letras, del lado de la vida o de la muerte. Las paronomasias a partir de las que Pascal Quignard lee y traduce a Celan muestran lo peligroso, lo doloroso que pueden ser tales cambios de significado: en "Mangel" (falta), está también "Mandel" (almendra), es decir, en la pérdida se encuentra también la salvación, la leche que da vida, el regreso del muerto, los muertos que no mueren. Y la diferencia no reside más que en una letra. 
Ya que, nos dice Pascal Quignard en Requiem, "no sólo hay muerte en la muerte" (2006: 59). De ella, en todo momento puede resurgir la vida, como las flores nacen de los cadáveres: "Se entierran a los muertos como se entierran las semillas, en previsión del rebrote en el 'primum tempus' en el que cada primavera se abreva" (Quignard 2010: 277).

En las letras, en su desplazamiento, se pone en juego también la cuestión del duelo y de su realización: "No es siquiera seguro, escribe en Vida secreta, que exista para la especie humana algo como el duelo" (Quignard 1998: 151). El dolor de la pérdida es ciertamente inconsolable. Llanto y lamentación puntean su escritura. Pero la traducción ofrece también la posibilidad de encontrar ese "tú sin muerte", que figura de cierta manera en el relato de la reina Artemisia que "confeccionó" un "mausoleo para Mausolo". Quignard retoma el relato de Cicerón (Tusculanas, III, 75) de ese duelo que se conserva "imputrescible" gracias a la ingestión voluntaria de las cenizas del esposo. Para acentuar este lazo con el muerto, Quignard decide traducir "recens", que en Cicerón, según nos señala, califica el dolor de la reina de una manera más temporal, como "fresco": "Era a tal punto [...] que Artemisia podía pensar que su dolor se conservaría siempre 'fresco' [...] porque la sangre lo irrigaba y renovaba constantemente" (Quignard 1998: 266-267).

En la traducción se encuentra algo de este orden que desplaza los términos y nos hace comprender de otra forma la relación entre la vida y la muerte.

"Eros defunto y Tanatos renaciente" (Quignard 1998: 159).

BIBLIOGRAFÍA

Berman, Antoine. La traduction et la lettre ou l'auberge du lointain. Paris: Seuil, col. L'ordre philosophique, 1999.

Blanchot, Maurice. Le dernier à parler. Paris: Fata morgana, 1984.

Celan, Paul. "Die Silbe Schmerz", La Rose de personne / Die Niemandsrose, trad. Martine Broda. Paris: Seuil, col. Points Poésie, 2002.

Gorrillot, BÉnÉdicte. "Le latin de Pascal Quignard”, Pascal Quignard. Figures d'un lettré, Paris: Galilée, 2005. 
Klossowski, Pierre. En Antoine Berman, "L’Énéide de Klossowski”, La traduction et la lettre ou l'auberge du lointain, Paris: Seuil, col. L'ordre philosophique, 1999.

Quignard, Pascal. Une gêne technique à l'égard des fragments. Paris: Fata morgana, 1986.

Quignard, Pascal. Vie secrète. Paris: Gallimard, 1998.

Quignard, Pascal. Petits traités I [1990]. Paris: Gallimard, col. Folio, nº 2976, 2002.

Quignard, Pascal. Requiem. Paris: Galilée, 2006.

Quignard, Pascal. Lycophron et Zétès [1971-2010]. Paris: Gallimard, col. Poésie, 2010.

Quignard, Pascal. "Autour d'Inter aerias fagos", entretien inachevé avec Bénédicte Gorrillot, 9 février 2009, inédito, citado en Mireille Calle-Gruber (ed.), Pascal Quignard ou la littérature démembrée par les muses. Paris: Presses de la Sorbonne Nouvelle, 2011a.

Quignard, Pascal. INTER. Ed. Bénédicte Gorrillot, trad. Pierre Alferi, Eric Clémens, Michel Deguy, Bénédicte Gorrillot, Emmanuel Hocquard, Christian Prigent. Paris: Argol, col. L'Estran. Poésies contemporaines, $2011 b$.

Quignard, Pascal. Leçons de solfège et de piano. Paris: Arléa, 2013. 